\title{
Experimental effects of surfactants on the production of stromatactis-shaped cavities in artificial carbonate sediments
}

\author{
JINDŘICH HLADIL, LEONA KOPTíKOVÁ, MAREK RŮŽIČKA \& LUKÁŠ KULAVIAK
}

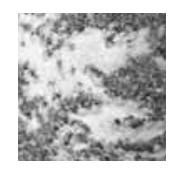

\begin{abstract}
This study continues previous work on the fluid-mechanical/rheological origin of stromatactid cavity systems. In contrast to our previous work, this study focuses specifically on the role of liquids in settling slurries. Experiments with increasing amounts of surfactants (and other solutes) in water provided evidence that the formation of stromatactis-shaped cavities can be significantly reduced, increased or structurally modified in this manner. Two artificial 'mud-based', complex particulate materials were used, simulating the compositions of their natural counterparts: a 'clastic mixture' and a 'sponge spicule mixture'. Three results are particularly significant: Firstly, the magnitude of volumes of stromatactis-like cavities initially falls and then increases, with the lowest values corresponding to the initial amounts of surfactants. Secondly, a nearly perfect match between the behaviours of the two different materials was found. And, thirdly, the largest and most typical cavity shapes were experimentally produced under conditions of moderately increased surfactant concentrations, whereas subsequent over-saturation lead to the formation of massive infills instead of well preserved voids. $\bullet$ Key words: surfactants, polydisperse particulate systems, multiphase systems, pattern formations, experimental sedimentation, voids in sediment, carbonate sediments, stromatactis.
\end{abstract}

HLADIL, J., KOPTíKOVÁ, L., RŮŽIČKA, M. \& KULAVIAK, L. 2007. Experimental effects of surfactants on the production of stromatactis-shaped cavities in artificial carbonate sediments. Bulletin of Geosciences 82(1), 37-50 (6 figures). Czech Geological Survey, Prague. ISSN 1214-1119. Manuscript received July 29, 2006; accepted in revised form February 26, 2007; issued March 30, 2007. • DOI 10.3140/bull.geosci.2007.01.37

Jindrich Hladil, Academy of Sciences of the Czech Republic, Institute of Geology, Rozvojová 269, 16500 Prague 6, Czech Republic; hladil@gli.cas.cz・Leona Koptíková, the same address as the first author and Charles University, Faculty of Science, Institute of Geology and Palaeontology, Albertov 6, 12843 Prague 2, Czech Republic; koptikova@gli.cas.cz・Marek Růžička, Academy of Sciences of the Czech Republic, Institute of Chemical Process Fundamentals, Rozvojová 135, 16500 Prague 6, Czech Republic; ruzicka@icpf.cas.cz•Lukáš Kulaviak, the same address as the previous author; kulaviak@icpf.cas.cz.

The natural occurrence of stromatactis has been variously studied for more than a century (as reviewed by many authors, e.g., Bathurst 1982, Dieken 1996 or Neuweiler et al. 2001). The stromatactis are particular, usually centimetre- and decimetre-sized, imperfectly separated to interconnected, cement- and sediment-filled objects (initially holes) that are embedded in some carbonate sedimentary rocks. The basic characteristics used for their definition are shape, the nature of their infilling, and place of occurrence.

1. - The sub-horizontally extended shape consists of a relatively flat base and a domical, fractal-shaped upper part with a variety of protrusions. To use a rough simile, the vertically sectioned parts of the stromatactid system may resemble lenses, cock's combs or elkhorn corals, all with domical or dish-shaped varieties. They are confined to horizons in which they have single to multilayer arrangements, and the individual levels frequently appear as vertical and horizontal reticular (mesh) networks
(Hladil 2005). These objects are often recurrent in thin or thick series of successive sheets of sediment.

2. - Their infill consists mainly of geopetal sediment and isopachous, fibrous or bladed calcite cements of early marine cementation stages. Despite their considerable variability, two elements of these infills are very common. The first is the earliest deposition of the internal sediment, which is geopetal, imperfectly separated from the floor of the cavity, relatively fine-grained, and non-intermittently becomes finer upward. The second is the early formed, concentrically arranged marine cement with isotopic compositions equal to brachiopod calcite (Kaufmann et al. 1999, Kaufmann \& Wendt 2000). Other constituents correspond to subsequent, consecutive internal processes in the rocks, which form complex structures of diverse types (as simplified in Fig. 1A-T).

3. - The stromatactis occurrences are, however, highly interconnected with stratigraphic swells in the middle 
depths of carbonate slopes, often below the photic and wave zones but linked to microbialite material and organomineralization. These carbonate bodies with uneven or indistinct bedding planes have been traditionally assigned to mudmounds, carbonate mounds or deep-water non-skeletal reefs (e.g., Pratt 1995, Monty 1995 or Boulvain 2001). The stromatactis are virtually absent in areas of shallow-water carbonate reefs, and the same is true for deep-water rhythmites deposited from low density turbulent suspensions or under conditions governing debrisflow deposits.

The opinion that these stromatactis shapes basically copied the early voids in the natural carbonate sediments is favoured in many modern studies, being based on the successions of internal sediment infills and the generations of carbonate cements (e.g., Bathurst 1982, Neuweiler et al. 2001). However, the question of how these voids originate has remained a matter of major research concern. The modern literature concentrates predominantly on developing the concept of polymud fabric by Lees \& Miller (1985), so that the accreted stromatactis-bearing banks would contain significant amounts of autochthonous material and form a diagenetic buildup that would not exist without the action of organomineralization (Bourque et al. 2004). Subject to these or similar conditions, Lees (1964), for example, argued for downslope movement in some cases; Pratt (1982) made the case for a microbial framework and winnowing; Wallace (1987) proposed the mechanisms of internal erosion and sedimentation; Pratt (1995) also noted that some sheet-like cavities were probably seismically opened; Aubrecht et al. (2002) suspected the importance of the presence of mucilaginous aggregates; Woods (2002) suggested the role of subcutaneous fluid escape; Sanders (2003) emphasised syndepositional chemical dissolution; Krause et al. (2004) recently claimed that some are from clathrates; Neuweiler \& Bernoulli (2005) inferred that the natural stromatactis structures would be explained in terms of maturation of particulate polymer gels, syneresis-type

Figure 1. Stromatactid cavity systems in carbonate slurry beds, with emphasis on the transformation of primary stromatactum chambers into stromatactis as a diagenetic end product. Equally sized windows in the diagram correspond to several centimetres. The essentials of an alternative, 'non-reef' (event-sediment) concept are shown in the lowermost part; not to scale. $\bullet$ A-D - unstable voids in sediment and rapid infilling with ambient sediment or finer-particle infiltrates. • A - in the earliest sediment-consolidation stage, an elementary stromatactum cavity underlies the relatively firmly packed zone (arching effect - arc), whereas the fine-grained suspensions are initially pushed out (escape-esc). The floor of this primitive cavity initially consists of softer, still fluidized material which sinks downward (snk). B - these processes (as shown in A) closely precede the deposition of the first internal sediment (fis), which consists of material settled from residual suspension of the cavity and the nearby pores. The subsequent compression of the cavity causes the deformation of this first internal sediment. $\bullet \mathrm{C}-$ an unstable cavity is filled with large amounts of early infiltrated sediment (eis). $\bullet$ D - with the early collapse of the cavity, the fine-grained residual and infiltrated materials combine with the ambient sediment, resulting in specific, dish-structured (dsh) to mottled/wispy-laminated rock fabrics. $\bullet$ E-H - medium stable stromatactum chambers and alterations of their shape. $\bullet$ E - the chamber has a typical shape with fractal-like outlines (flo) in its upper part. The first internal sediment (fis) is a strictly geopetal fill with a diffuse bottom and very sharp surface. At this surface, the sedimentation microenvironment is very calm, and rare, ephemeral faunas of possibly psychrophyllic scavengers can occur (e.g., ostracods - ost). $\bullet \mathrm{F}$ - the shape of the stromatactum cavity is modified by bubbles (bub) from the admixture of decayed organic matter. $\bullet \mathrm{G}$ - partial breakdown of the cavity with falling clasts (parts of the sediment detached from the roof the chamber - flc). These clasts slightly sink into the still unlithified geopetal fill. $\bullet \mathrm{H}$ - breakdown after the collapse of the cavity vault. The layer of the first internal sediment becomes deformed (dfs). $\bullet$ The next three rows (I-T) illustrate the most common alterations of typical stromatactum cavities in carbonate rocks, when the consolidated sediment structures are firm enough and allow further hardening by cementation or recrystallization. $\bullet$ I-L - typically formed, stable stromatactum chambers and their early diagenetic transformations into complex structures. $\bullet$ I - the stromatactum chamber is firm and durable. In addition to the first internal sediment (a strictly fining-upward microsequence), large but low-density (porous, light) bioclasts can be deposited from the relict suspension (e.g., crinoid ossicle oss). $\bullet \mathrm{J}$ - the chambers of an interconnected system can be subsequently filled by a second generation of internal sediments (sis) which have laminae of variable grain-sizes, and are frequently winnowed. $\bullet \mathrm{K}$ - if well lithified, the chamber in an interconnected stromatactum cavity system can be modified into a corrosion hole (crh). $\bullet \mathrm{L}$ - the remaining open space (with both the original and corrosional walls) starts to become filled by concentrically layered bands of early marine cements (fibrous and bladed calcite cements with numerous inclusions - fcc). However, this process of cement growth can be interrupted by deposition of the third generation of internal sediment (tis). $\bullet \mathrm{M}-\mathrm{P}-$ a textbook example how the change from the stromatactum cavity into stromatactis structure can proceed. Common accompanying objects are involved (microstromatactis or stromatactoid fenestra-msf; shells and skeletons with chambers, e.g., cephalopods, brachiopods, corals $-\mathrm{shl}) \cdot \bullet \mathrm{M}-$ a firm stromatactum chamber. The small stromatactoid fenestra and chambered shell contain much less internal sediment in comparison with the stromatactum. $\bullet \mathrm{N}$ - concentrically layered bands of early marine cements start to grow (fcc-1), particularly in the largest cavity which is interconnected with other cavities in the stromatactid cavity system. $\bullet \mathrm{O}-$ the zonal, almost isopachous growth of marine cements continues (fcc-2). The isolated small cavities have, however, only thin coatings of these cements on their walls. $\bullet$ P - The equant, drusy mosaic spar cements ( $\mathrm{msc}$ ) occur in very late stages. $\bullet$ Q-T - other changes that accompany the transformation from primary stromatactum cavity to stromatactis. $\bullet \mathrm{Q}$ - the early contraction fractures (ecf) in consolidated sediment, containing loose grains and slightly lithified microfragments. $\bullet$ $\mathrm{R}$ - with recrystallization of the host rock (and precipitation of the first fibrous cements), replacive calcite aggregates (rca) can modify the former cavity rims. Early zebra-like (zls) or parallel bedding splits soon follow the earliest stromatactid cavity systems, as well as the first fractures and veinlets (fvs) in the lithified rocks. $\bullet S$ - rare horizontal stylolites with their extensional fractures (bps) cut a few of generations of the first fractures and veinlets. $\bullet$ $\mathrm{T}$ - structures such as vertical tectonic stylolites (vts), together with accompanying or subsequently generated fractures and veinlets, cut or cross all previous structures. $\cdot \mathrm{U}$ - event-sediment origin of stromatacta. Evidence suggests that stromatacta are the earliest of all structures formed in these sediments. Their first internal sediment directly continues the main phase of instantaneous sedimentation, i.e. they must exist as cavities from the beginning. These systems would finally become intrinsically linked within the middle parts of slurry beds. 
STROMATACTUM/STROMATACTIS: VARIATION AND CHANGES

stromatactum - as an environmentally specific, absolutely earliest hole in the sediment

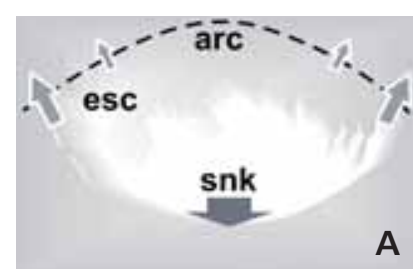

A

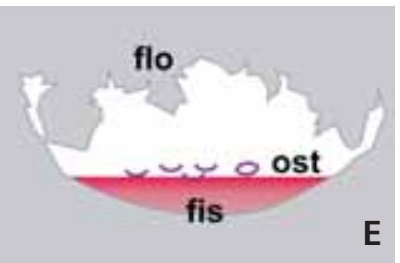

E
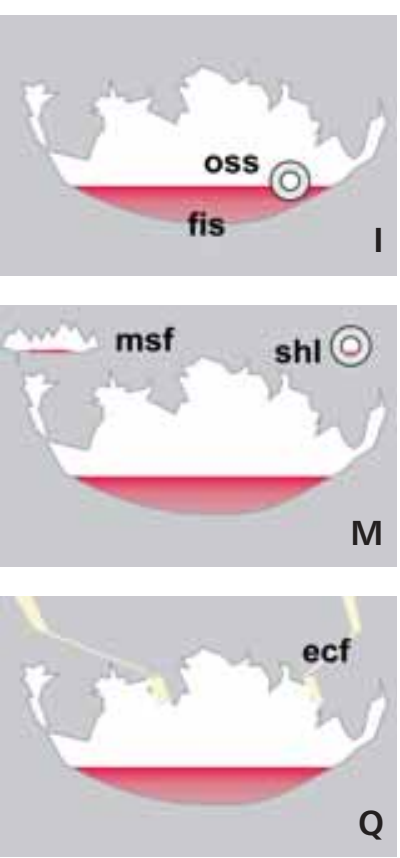
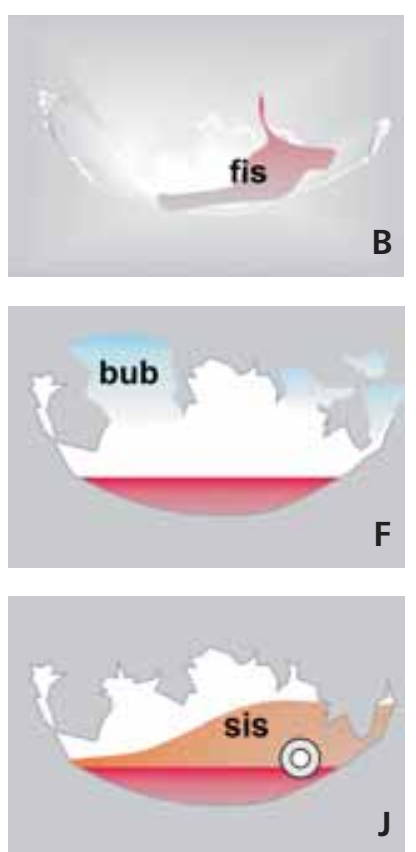

(O)
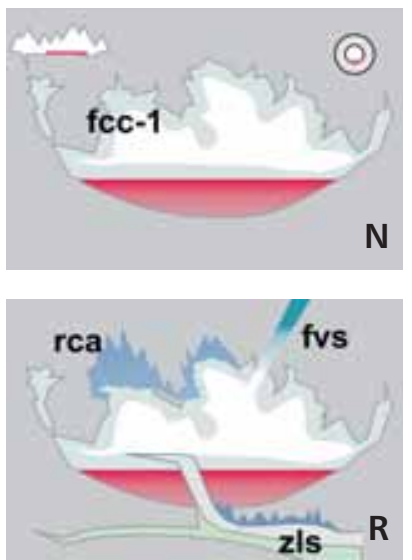

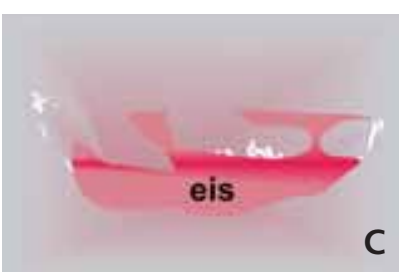

C
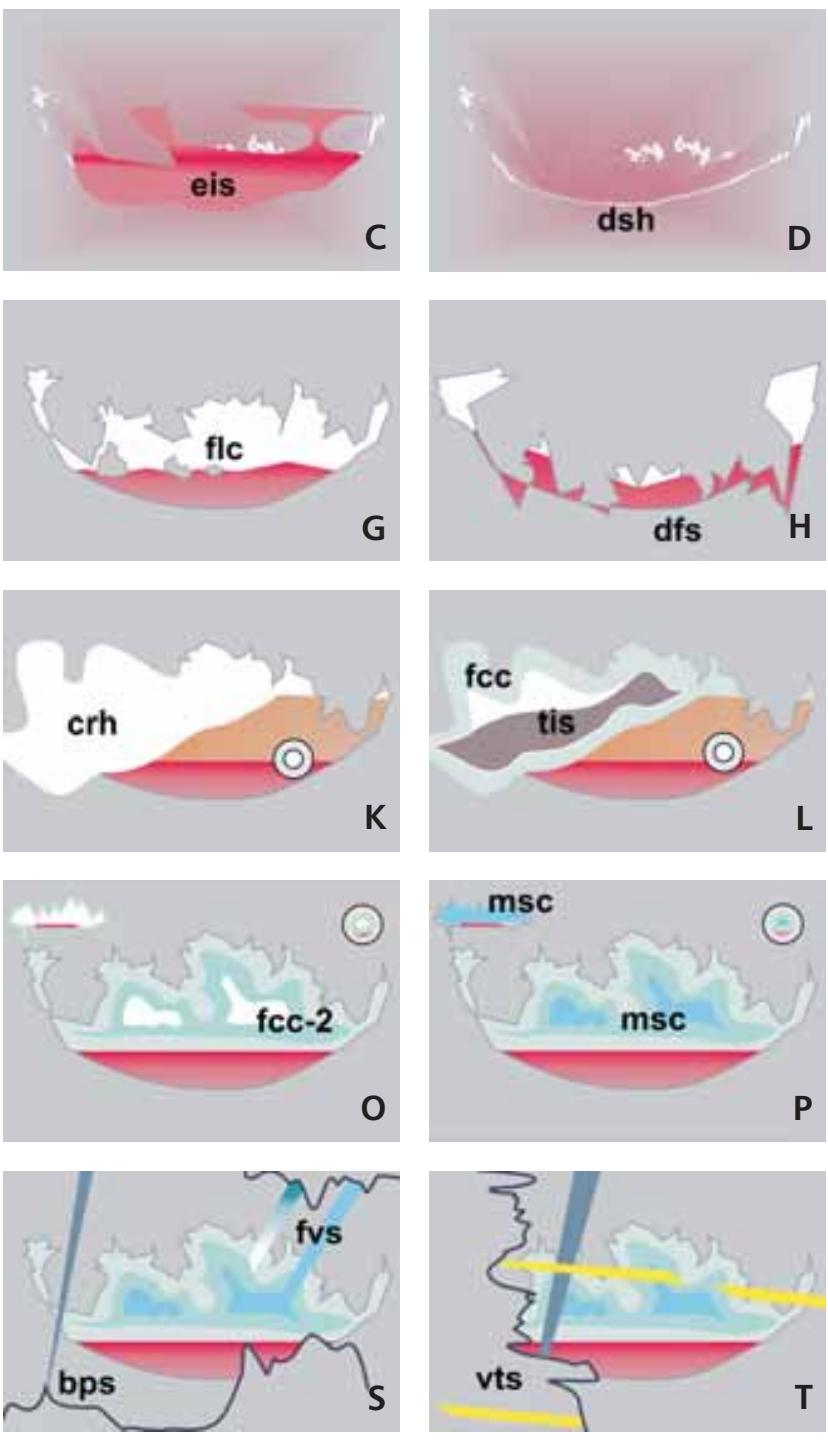

stromatactis - as final diagenetic structure

\section{EVENT-SEDIMENT SCENARIO FOR STROMATACTIS-BEARING BEDS}

\section{medium-dense}

turbidity current,

(polydisperse, multimodal, high-friction material)

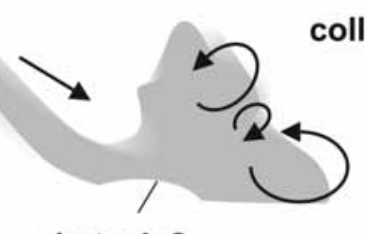

obstacle? collapse, subvertical sedimentation, evolution of inhomogeneities

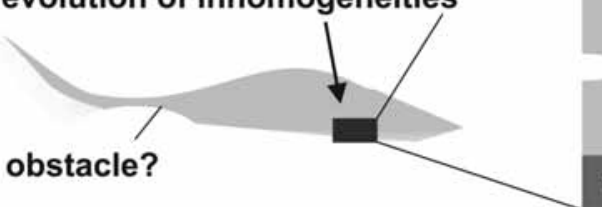

fine grained

upper sealing layer $\quad$

slurry layer with inhomogeneities

well-packed basal layer 
deformation and calcite mineral authigenesis; and Delecat \& Reitner (2005) revived the idea that stromatactis form from decayed sponges. These are just a few examples of the many concepts that have been discussed in the literature of the past few decades.

A critical reinvestigation of rocks in which stromatactis occur (mainly from the Lower Devonian of the Barrandian area, including the consideration of other comparable natural occurrences and experimental work: Hladil 2005, Hladil et al. 2006) has led to a new concept for the origin of the stromatactid cavity systems involving the fluid mechanics and rheological properties of particulate sediments. There are six basic reasons for this new concept:

1. - Succession of diagenetic changes: All observable, in-situ diagenetic changes occurred after the formation of the precursor cavity system or its individual chambers (Fig. 1A-T). This could happen only if the original sediment was not slowly accreted but deposited in a single event.

2. - The initial internal sediment: These earliest geopetal infills have an indistinct base (unconsolidated cavity floor), a continuous fining-upward trend, and a smooth, water-level termination (reflecting a temporary stage of absolute calm within the cavity). The formation of the voids and the first infills must represent two stages of one uninterrupted, very short process.

3. - Composition of the sediment: The well-preserved, unaltered stromatactis host rocks show mud-forming materials of extremely polydisperse and multimodal to gapped distributions, and the same is usually true for the regularly admixed coarser components. Most of the grains are very angular or indented, and thus potentially cause increased shear stress (or yield stress and internal friction, respectively) in these thickening carbonate materials and allowing the formation of voids directly during the deposition event.

4. - Stromatactis position in the bed: True stromatactis arrays are spread subhorizontally throughout the middle of the beds in which they occur, but are absent in the usually finer-grained upper parts and the usually coarser-grained lower parts. Contacts between the beds are faintly developed, and are often indented or complicated by shallow truncations. This regular position corresponds to the event-sediment concept (Fig. 1U), and is generally consistent with the position of dish-structured objects in slurry beds (e.g., Lowe 2000, Lowe \& Guy 2000). These dishes (Fig. 1D) may serve as a link between the carbonate and flyschoid non-carbonate slurry beds.

5. - The stromatactis formations in their narrow definition (Dupont 1882 - Bathurst 1982) occur throughout a variety of biofacies (including crinoids or sponges), bathymetric ranges, and forms of stratification (single or multilayered, strictly planar beds, dome-shaped 'mounds', or rare dished beds of inter-reef depressions). The factors de- termining the formation of stromatactis must, therefore, be fairly universal, involving the material composition and mode of sedimentation.

6. - The experimental slurry-sedimentation of complex, predominantly fine-grained, extremely polydisperse, multimodal particulate mixtures containing angular and indented grains (as an analogue to host-sediment compositions) has provided evidence that cavity systems of adequate geometry and features of immediately subsequent internal sedimentation can be produced in a markedly brief time (Hladil 2005, Hladil et al. 2006).

During these studies, the problem of differentiating between the primary cavities and the final diagenetic formations of stromatactis became a significant issue (both actually and concerning the terminology). Hladil \& Růžička (2006) suggested a tentative solution to this problem by introducing the new term 'stromatactum' (pl. stromatacta) for stromatactis-like cavities in artificial, carbonate event-sediments and their hypothetical natural counterparts. Using this concept, the succession of changes relating to stromatactis formation can be described from the first to the last stage, i.e. from stromatacta to stromatactis (Fig. 1A-U).

The first paper of the present series (Hladil 2005) concentrated on substantiating the hydrodynamic concept, and showed that voids of stromatactis-like shape can be artificially produced. The second paper (Hladil et al. 2006) dealt with mechanisms of the transition between the suspension and granular-flow phases, and was mainly focused on the role of coarser-grained accessories. The present contribution is a preliminary investigation of another aspect of settling slurries: the influence of surfactant concentrations in water.

The main reason for this most recent round of experiments is the fact that seawater contains considerable amounts of dissolved salts, organic radicals and mixtures of different ionic and undissociated constituents, also containing colloidal particles and floccules, often forming a continuum between dissolved and particulate matter (e.g., Verdugo et al. 2004). Concentrations of these constituents must influence the density, viscosity and shear stress of such aqueous solutions, and exercise a significant effect on the surface layers of the particles.

\section{Materials, methods and procedures}

Mixtures of particulate materials. - First, a relatively common mixture containing mud and clasts was prepared. This artificial 'clastic mixture' (Fig. 2) approximates the natural compositions of the more bioclastic types of stromatactis host sediments (e.g., Boulvain 2001, Schmid et al. 2001, Hladil 2005, Aubrecht et al. 2006). For this case, a 55 wt.\% prevalence of typical mud-forming materials was set (con- 
"CLASTIC MIXTURE"

\section{COMPONENTS (MATERIALS)}

Ic

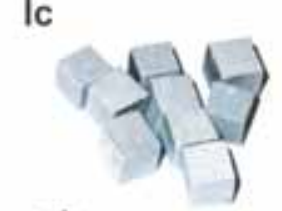

ab

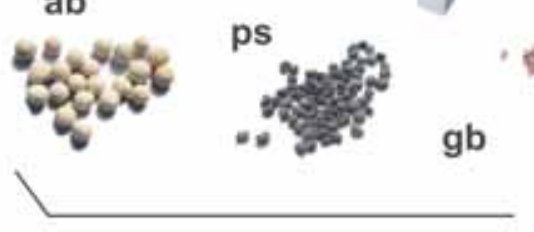

mc

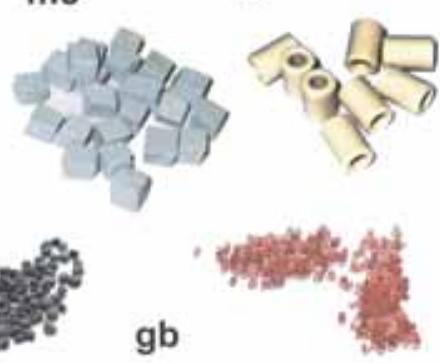

"SPONGE-SPICULE MIXTURE"

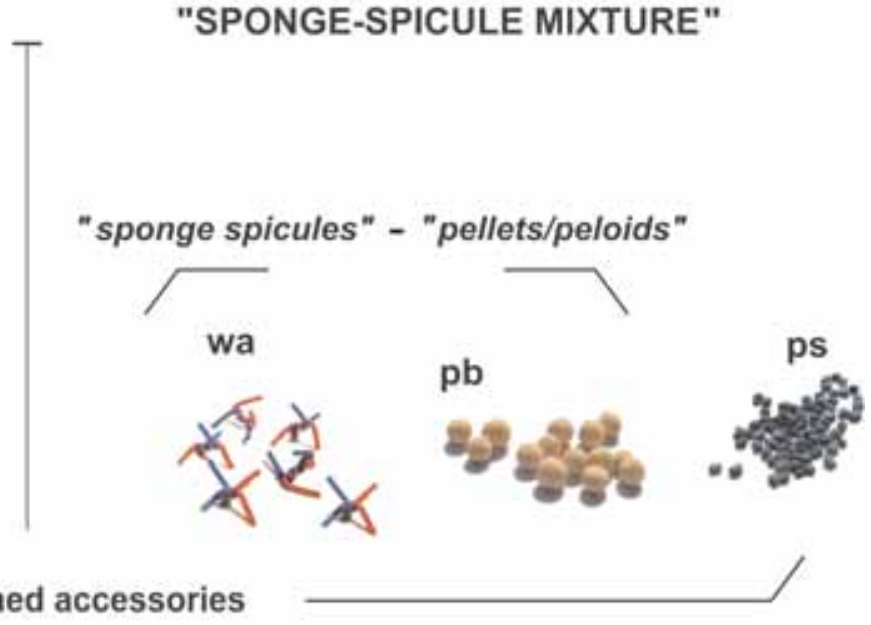

\section{AND THEIR PROPORTIONS}
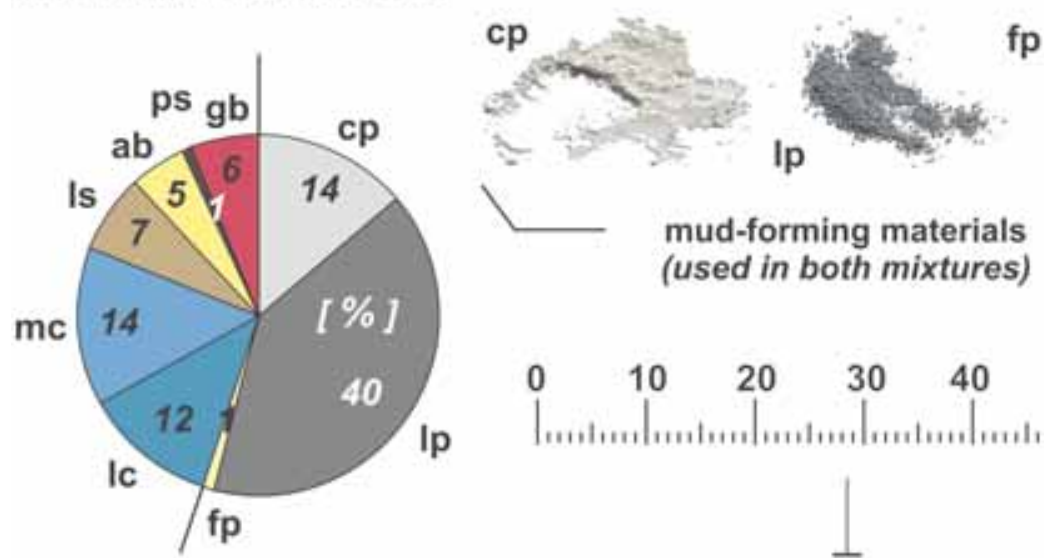

fp
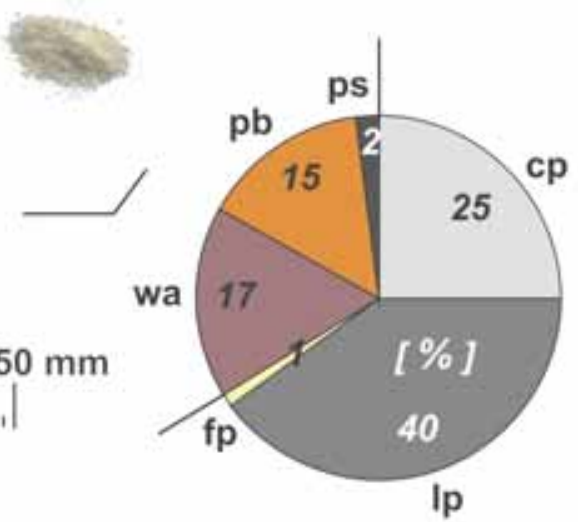

Figure 2. Composition of artificial particulate mixtures used for experiments. Universal 'mud-forming' components: $\mathrm{cp}$ - powdered calcite, lp - powdered limestone, fp - coarse flour, organic material. Additional 'clastic mixture' components: lc - large cubes cut from dental plaster, mc-medium sized cubes, the same material, ls - large ceramic/steatite, hollowed cylinders, ab - alumosilicate/nanosieve beads, ps - poppy seeds, gb - glass beads. Additional 'sponge-spicule mixture' components: wa - plastic coated wire anchors ('spicules'), pb - aluminosilicate beads, expanded and slightly impregnated with arabic gum ('soft pellets'), ps - poppy seeds. For further details on these materials, see the Materials, methods and procedures section.

sisting of three components), and the remaining amount (45 wt.\%) of solid particles was composed of medium to coarse-grained materials of various sizes, densities and shapes (six components). The fine-grained, mud-forming materials consisted of 1-10 (5) $\mu \mathrm{m}$ grains of powdered calcite, 2-250 (125) $\mu \mathrm{m}$ grains of powdered 95\% pure limestone, and coarse flour organic material (Fig. 2). The coarse-grained accessories were composed of 5 and $3 \mathrm{~mm}$ cubes cut from dental plaster, hollowed cylinders of cera$\mathrm{mic} / \mathrm{steatite}, 6 \mathrm{~mm}$ in length, alumosilicate/nanosieve beads $2 \mathrm{~mm}$ in diameter, and poppy seeds and glass beads $0.5 \mathrm{~mm}$ in diameter (Fig. 2). Second, a mixture with 'mud', 'spicules' and 'soft pellets' was prepared. The preparation of this mixture was based on the observation that many natural stromatactis host rocks contain sponge spicules (even complex ones, e.g., tetraxonid, polyaxonid or anchor-like shapes), and they can occur together with soft/semi-solid pellets, peloids or clumps of micrite/organic material (e.g., Bourque \& Gignac 1983, Neuweiler \& Bernoulli 2005, Delecat \& Reitner 2005). This artificial 'sponge-spicule mixture' (Fig. 2) was prepared for the first time in the three-year history of these stromatactis experiments. The mud-forming materials predominated (66 wt.\% of solids, the same three components mentioned above; Fig. 2). In the remaining amount of accessory grains (34 wt.\%), roughly equal preponderance was given to imitation sponge spicules and soft pellets. The former were imitated using the plastic-coated thin-wire anchors, and the latter consisted of aluminosilicate beads that were first expanded and then slightly impregnated with arabic gum, and finally coated by a film of the finest calcite powder. These beads had surfaces that were moderately soft and plastic, and very slightly adhesive on contact. A minor amount of tracing and destabilizing poppy seeds was also added to the mixture (Fig. 2). 


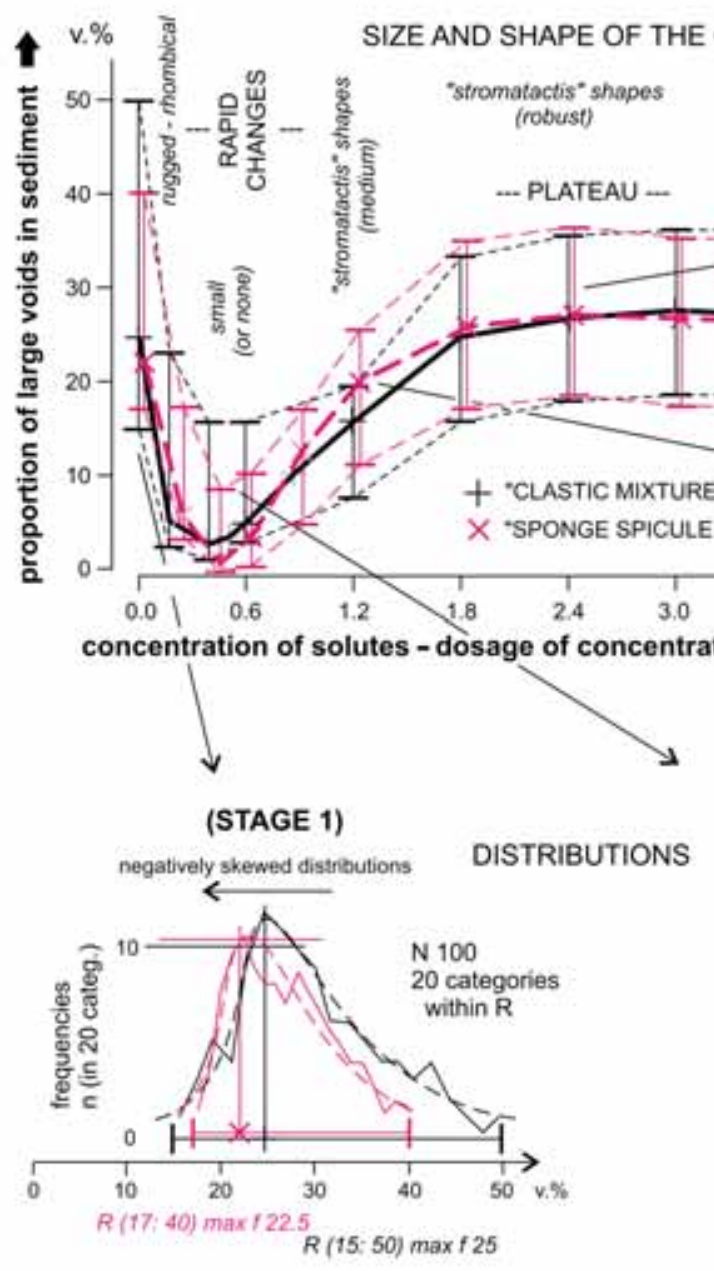

(STAGE 2)

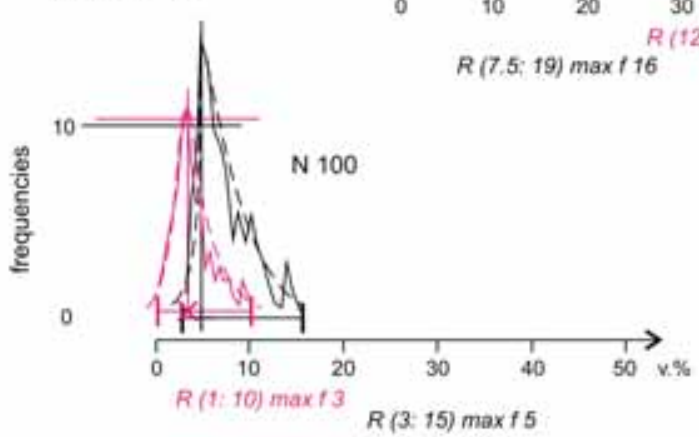

Figure 3. Results of the laboratory experiments. This diagram shows how magnitudes (volumes) and types of stromatactid voids in sediment correspond to the concentrations of surfactant-bearing detergent solutions. The four stages correspond to different concentration levels; black graphs for 'clastic mixture', red for the 'sponge-spicule mixture'.

Fluids. - A water/solid volume ratio of 2 was used for the experiments reported in this paper. The initially applied medium was distilled, deionized water. Because mixtures of dissolved salts and dissociated or strongly polar organic molecules in combination with sub-colloids/colloids behave as surfactants or emulsifiers/flocculants, a highly concentrated solution of household dish detergent in water was selected as a convenient complex substance, roughly relevant for the purpose ('Jar Lemon', Procter \& Gamble-Rakona Inc., annual production about 10 million kg). This concentrated solution, used for gradually increasing the amount of surfactants, contained $\sim 10 \mathrm{wt} . \%$ anionic and $\sim 5 \mathrm{wt} . \%$ nonionic compounds in water. The active chemical ingredients are as follows (in decreasing order): $[\sim \mathrm{n} \times 1 \mathrm{wt} . \%]$ sodium laureth sulphate $>\mathrm{C} 10-16$ alkylamine oxide $>$ C9-11 pareth- $8>$ sodium chloride $>$ polypropylene glycols $>$ ethanol $>1,3$-cyclohexanedimethanamine $>$ dimethyl aminoethyl methacrylate, hydroxypropyl acrylate copolymer citrate; [ n $\times 0.1 \mathrm{wt} . \%]$ sodium hydroxide > phenoxy ethanol $>$ dipropylene glycol $>$ benzisothiazolinone $>$ geraniol $>$ limonene. The undiluted detergent $(15 \%)$ had a density of $1.03 \mathrm{~g} / \mathrm{mL}$, while the slightly diluted solution (10\%) had a pH of 9. The dosage was expressed as weight per mil (wt.\%o) of this concentrated solution relative to pure water in the following increments: $1^{\text {st}}$ : without detergent $0 \mathrm{wt} . \% o, 2^{\text {nd }}: 0.6 \mathrm{wt} . \% o, 3^{\text {rd }}: 1.2 \mathrm{wt} . \%$, and $4^{\text {th }}: 1.8,2.4,3.0$ and $3.6 \mathrm{wt} . \%$. The concentrations from 1.8 to $3.6 \mathrm{wt} . \%$ were joined together in the fourth step because the differences within this interval were not statistically significant (see the Results below). A larger number of increments and their complementary series of experiments were necessary toward understanding the conditions relating to the interval between 0.0 and $1.2 \mathrm{wt} . \%$ and above $3.6 \mathrm{wt} . \%$.

Glassware $-250-\mathrm{mL}$ cylindrical laboratory bottles with a height/width ratio of about 1.2, with a screw stopper on the wide neck. 


\section{STAGE NUMBER}

\section{concentration of surfactant blend in water $[w t . \% o]$}
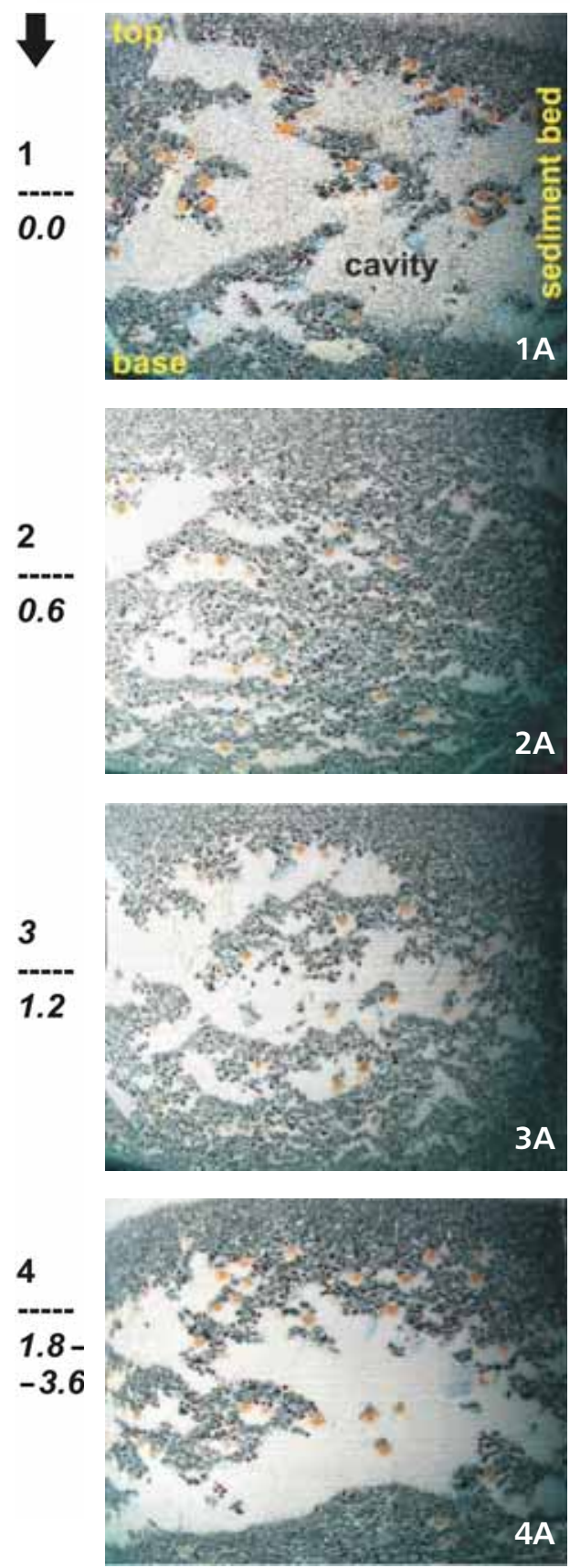

\section{"CLASTIC MIXTURE"} variability of cavity shapes (other examples)
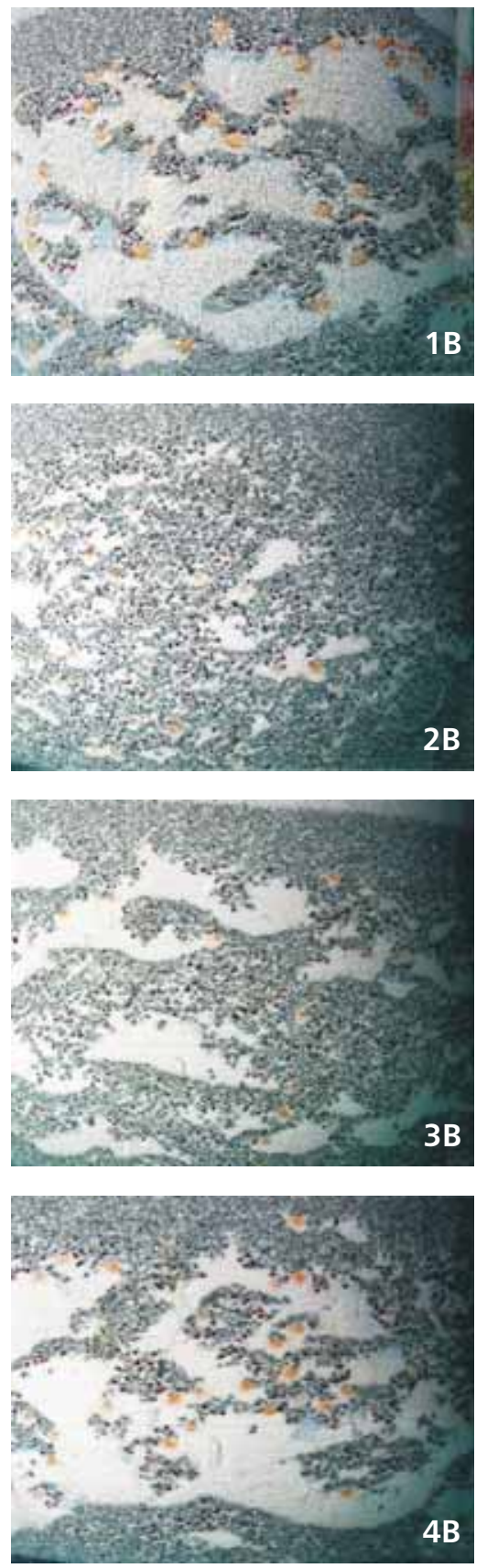

\section{B}

[ $\mathrm{mm}$ ]

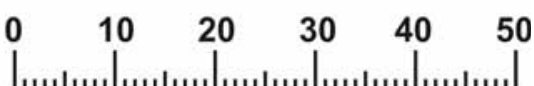

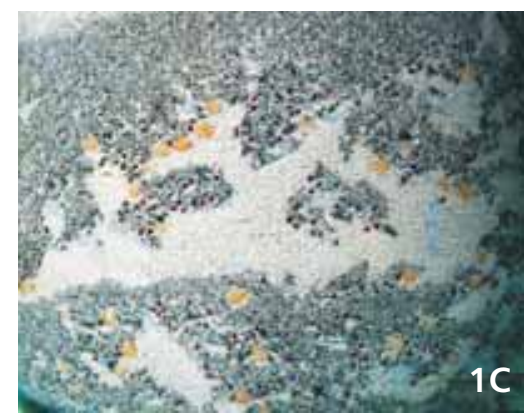
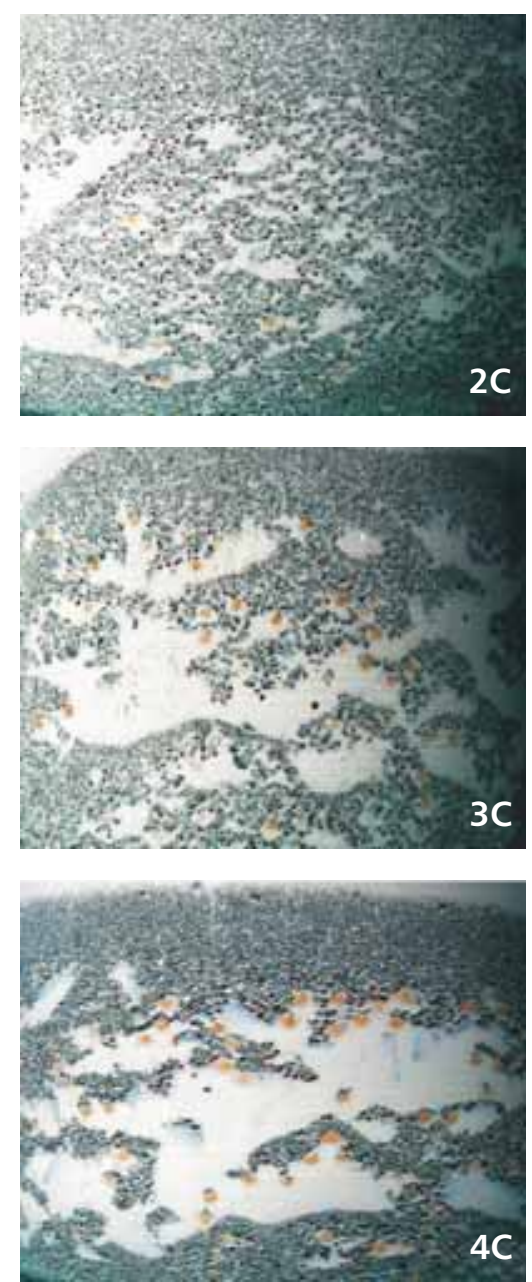

Figure 4. Illustration of the 'clastic mixture' experiments. Images of typical stromatactum-cavity patterns were obtained using the polydisperse-multimodal mud-forming materials with various complex-shaped, coarse-grained accessories. Vertical views of the beds sedimented in $250 \mathrm{~mL}$ laboratory bottles; photographs were taken 90 seconds after the formation of the bed; the base of the bottle is just below the lower edge of each photograph. The large whitish voids in the sediment were still filled by suspended grains of the finest, slowly sedimenting particles. The vertical columns of images (stages 1-4) correspond to graded concentration levels as adjusted amounts of detergent solution were added to the water. The three images in horizontal rows (A-C) illustrate the most characteristic results from the 100 repetitions of the sedimentation experiments. The succession shows strong responses to low concentrations of detergents, in which stromatactum-cavity formation was much reduced (2A-C). Next, an increase to moderate concentrations led to the restoration of stromatactis cavity formation $(3 \mathrm{~A}-\mathrm{C})$, though these cavities have more precisely shaped bottoms and ceilings in comparison to those of the initial detergent-free conditions (1A-C). With higher concentration levels, the size and shapes of the cavities are almost identical to those observed in many natural stromatactis structures. They were quite constant in magnitude $(4 \mathrm{~A}-\mathrm{C})$. 
Preparative mixing. - For the water/solid volume ratio of 2, we combined $170 \mathrm{~mL}$ of water and $80 \mathrm{~mL}$ of solids. Expressed in mass units, the solid fraction consisted of $190 \mathrm{~g}$ of proportionally added solid components for the artificial 'clastic mixture', and $210 \mathrm{~g}$ for the 'sponge-spicule' mixture. The initial preparation of the mixtures requires accurate and time-consuming processing due to the relaxation of absorbent materials and the repetitive adjustment of the compositions of these mixtures. Periodic shaking of the bottle (in 15 minute intervals) was necessary for sufficient removal of the microbubbles that formed during this relaxation. The experiments started exactly 6 hours after the first mixing. The addition of the detergent was the last step ( $0.5 \mathrm{~h}$ before use), and was done using a volume pipette.

Shaking and stopping methods, sedimentation. - The closed laboratory bottles containing the mixtures were positioned upside down, and their content were vigorously mixed using an irregular shaking motion. This shaking was done using adjustable triple shakers that were connected to the bottle by flexible holders. The shaking was stopped and restarted whenever a strong vortex or hydraulic structure evolved. Major dynamic impulses must occur on an average of 3 to 3.5 per second, and major radial distances from the midpoint must be 2.5 to $3 \mathrm{~cm}$ (both for these $250 \mathrm{~mL}$ bottles and mixtures as defined above). The movement to an upright position for sedimentation was done using a half-circle trajectory, and accomplished as quickly as possible but with deceleration at the end (i.e. quick unfastening from the shakers, rotation on the boom with an attached high-speed video camera, and a 'soft-landing' in the normal position on a 'sandy' substrate. This movement usually took about 1 second with a $30 \mathrm{~cm}$ boom. This motion can also be accomplished manually, though imperfect attempts must be carefully eliminated. Each experiment was repeated at least 100 times, and the reproducibility of the results was evaluated using high-speed video recording.

Photo-documentation of the voids. - The higher-resolution digital photographs of the void structures produced by the sedimentation/settling of the 'clastic mixture' and 'spongespicule mixture' slurries were taken about 90 seconds after the formation of the sedimentary beds. The windows through which these structures were viewed were $4 \mathrm{~cm}$ high and $5 \mathrm{~cm}$ wide. The bottom of each window was close to the base of the bottle (in the lower layer of sediment), while the top revealed the upper layer of the sediment, so that the entire middle section containing the stromatacta cavities was entirely visible. Only the very thin lowermost and uppermost parts of the bed were neglected, mostly because of locally varying thicknesses.

Processing the images. - Correcting for the cylindrical geometry of the vessels was necessary for obtaining a pla- nar image. Next, the gradients between the bright opalescent voids (stromatacta; still filled by the residual, slowly sedimenting suspension of finest particles) and darker coloured sediment were traced. The undersize pores $(<2 \mathrm{~mm})$ were neglected, and the remaining voids (mostly a few centimetres in size) were transformed into objects. The cumulative area of these objects (voids, stromatacta) in a planar vertical section (i.e. close to inner wall of the bottle) was calculated [\%]. According to previous experiments (Hladil 2005, and Hladil et al. 2006), the area ratio of voids/sediment must closely approach the volume ratio. Therefore, the vertical-section area percentage (proportion of stromatacta to the volume of the entire bed) has been directly converted into a volume percentage [v.\%].

\section{Results}

The sedimentation behaviours of two different stromatacta-forming particulate slurries were compared using the 'clastic mixture' and 'sponge-spicule mixture'. The most significant result is the nearly perfect match of the average reactions of both materials to equally increased concentrations of surfactant solution. Such a high degree of similarity suggests that the concentrations of surfactants have a universal influence on the magnitude and shapes of the stromatacta formations.

The first stable stromatacta shapes experimentally obtained with the surfactant-free sedimentation of both the mixtures (Stage 1; Figs 3-5) were voluminous, tending to have bulk rhombic shapes and broad diagonal-reticulate arrangements in the bed. The outlines of these cavities became discernible in less than one second, though they were slightly modified during the consolidation of the sediment over the subsequent 300 seconds. The images shown here were taken after the first 90 seconds, when the light-coloured residual suspensions were still buoyant, thus providing enhanced contrast between the voids and sediment. It is perhaps surprising that these residual suspensions did not consist only of the finest mud fractions, as even particles $\geq 10 \mu \mathrm{m}$ became entrained in these suspensions for more than 180 seconds. In these two mixtures there was a slightly longer pause between the formation of the stromatacta and the sedimentation of the residual suspension than in more simple 'crushed/powdered limestone mixtures'. However, the subsequent internal sedimentation was very fast, resulting in the deposition of homogeneous (rather than well-graded) sediment on the floors of these cavities. This relatively delayed but fast settling of heavy residual suspensions occasionally (but not always) started gravitational jet flows of fine and medium-sized particles. When this occurred, these cascade flows resulted in additional geopetal (and/or piled) depositions. The final stromatactum-void magnitudes in the 'clastic mixture' var- 


\section{STAGE NUMBER}

\section{concentration of surfactant blend in water [wt.\%o]}

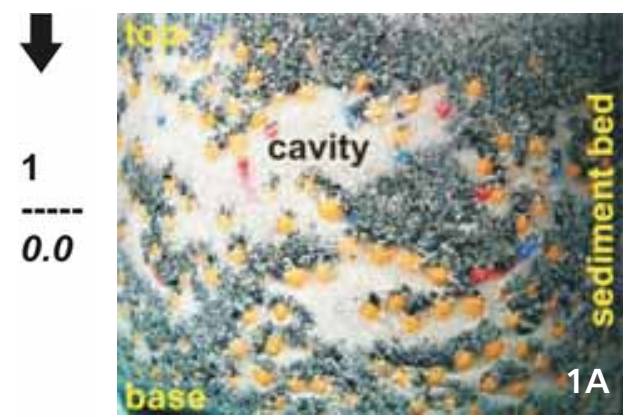

2

0.6
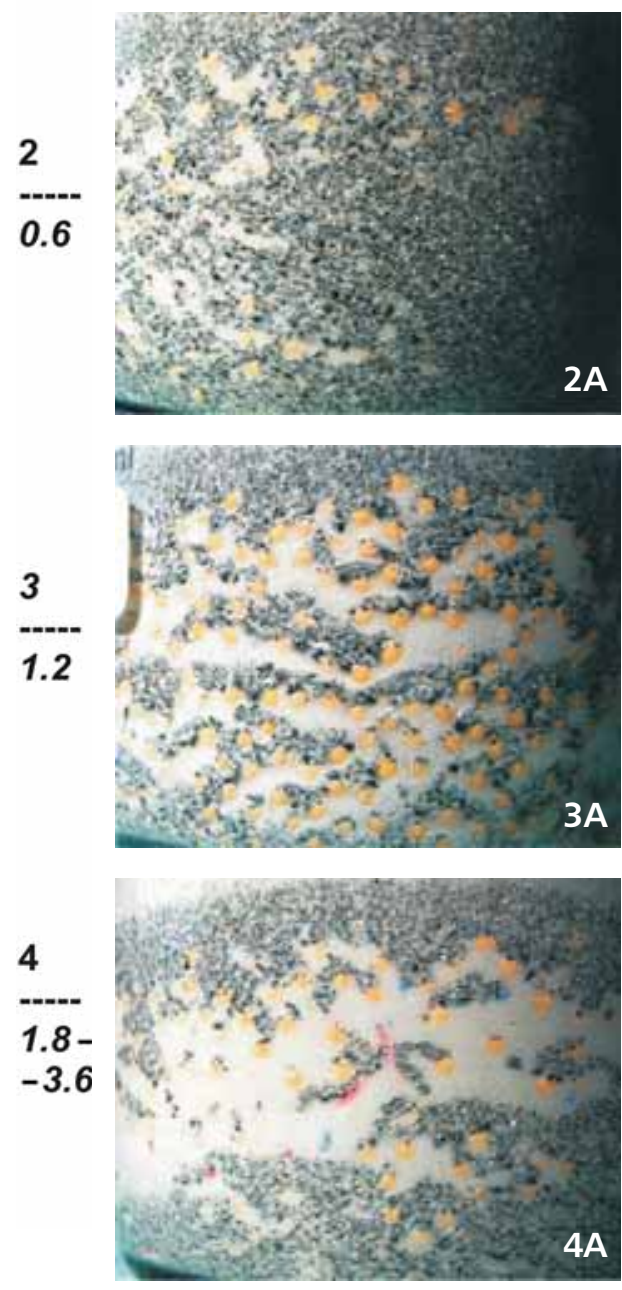

Jindřich Hladil et al. • Stromatactis-shaped cavities in artificial carbonate sediments

\section{"CLASTIC MIXTURE" variability of cavity shapes (other examples)}

\section{[ $\mathrm{mm}$ ]}

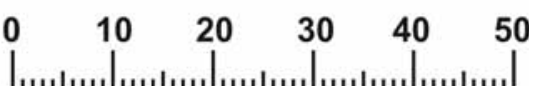

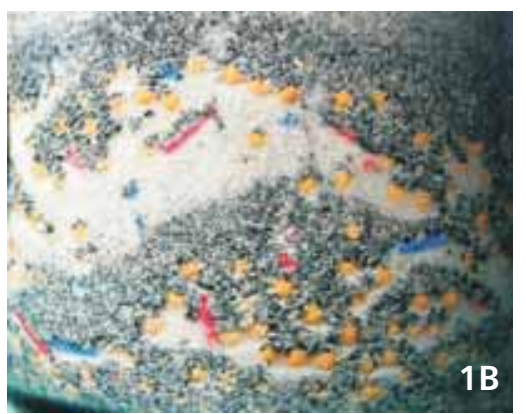
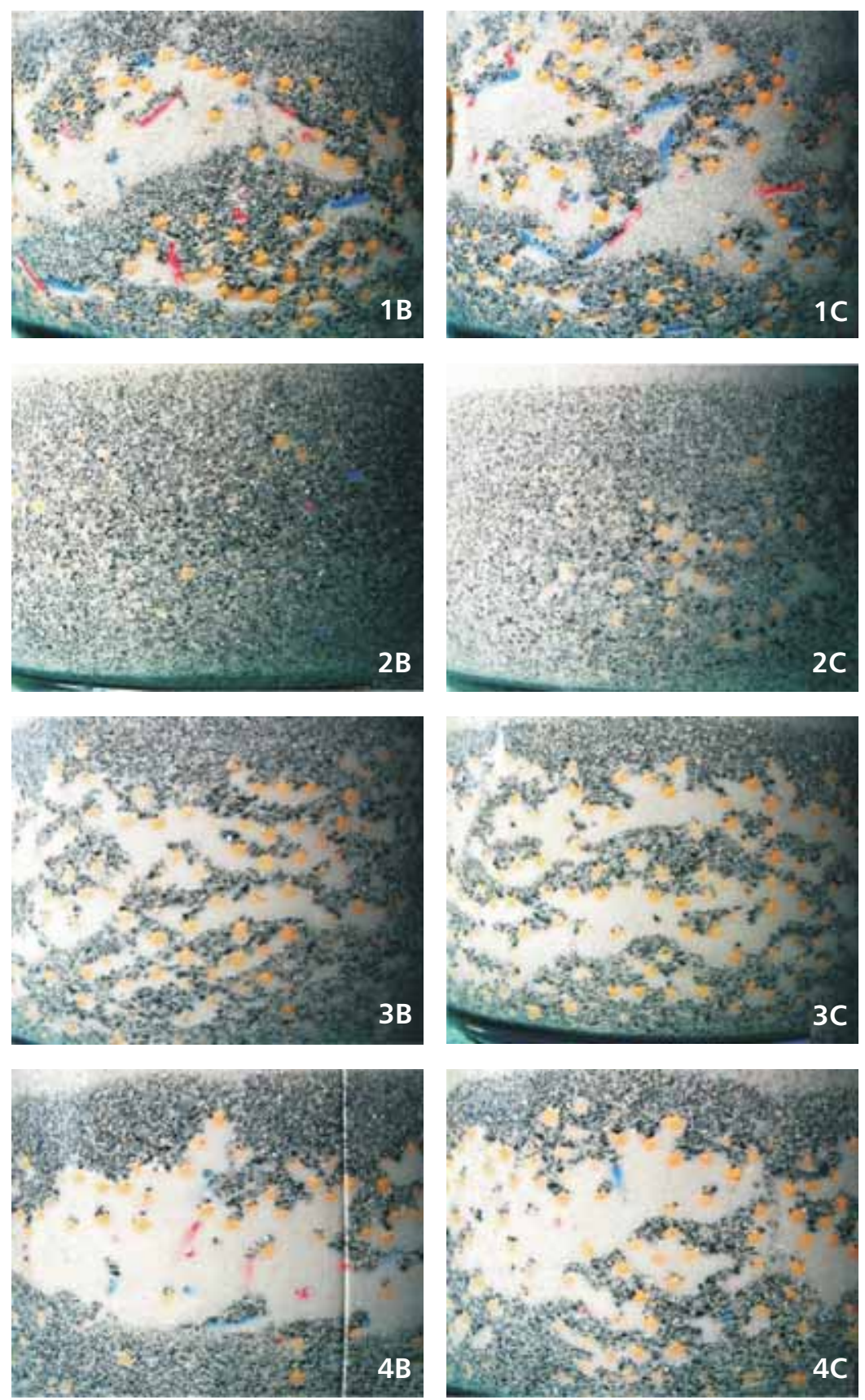

Figure 5. This array of images illustrates the behaviour of a newly introduced, artificial mixture of particles that simulates natural mixtures of mud, sponge spicules and pellets (peloids or clumps) that are partly soft and partly hard and adhesive. The working name of this mixture is the "sponge spicule mixture'. The arrangement of images in columns (1-4) has the same significance as in the previous figure (i.e. gradually increased concentrations of the surfactant solution). A significant reduction in the formation of stromatactum cavities occurred under conditions of low concentrations of surfactants $(2 \mathrm{~A}-\mathrm{C})$. With higher concentrations, the formation of stromatactum cavities was rapidly restored (3A-C). Soon after this recovery, it achieved a nearly invariable state, showing quite constant features (4A-C). 
ied from 15 to $50 \mathrm{v} . \%$ of the bed (with an exception for the thinnest lowermost and uppermost parts), with a negatively skewed distribution and a maximum frequency at $25 \mathrm{v} . \%$. For the 'sponge spicule mixture', these ranges were slightly reduced to 17 to $40 \mathrm{v} . \%$, and the distributions were similarly skewed and showed a maximum value at 22-23 v.\% (Fig. 3). The residual suspensions of the latter case (Fig. 5: $1 \mathrm{~A}-\mathrm{C})$ were slightly finer than in the former case. This slight difference must be caused by the initial proportions of the mud-forming components rather than the sedimentation processes themselves.

An abrupt change in the magnitude of the stromatacta cavities was triggered when the first dosages of detergent were applied (Stage 2; Figs 3-5). The stromatacta pattern formations were considerably reduced; the individual voids in the sediment were smaller and irregularly scattered, extending much farther from the middle level of the bed. The voids tended to form in layers (Fig. 4: 2A), irregular amoebic arrays (Fig. 4: 2B), or irregularly rhombic configurations (Fig. 4: 2C). Particles larger than $10 \mu \mathrm{m}$ were rare in the residual suspensions of these small holes. These experiments provide a glimpse of the extraordinarily strong effects of relatively small amounts of surfactants, i.e. in ranges around $0.5 \mathrm{wt} . \%$. The overall effect of these low concentrations on the stromatactum void-forming system was remarkably destructive. Furthermore, it is suggested in this case that stromatacta formation is not simply a rheological issue involving collapsed or filled voids (and the 'lubrication' of solid particles by surfactants), but that it is a hydrodynamic problem concerning small and unstable inhomogeneities together with the imperfect and unstable segregation and clustering of grains (e.g., compare the arrangements of yellow aluminosilicate and red glass beads in Fig. 4, Stage 1 vs. Stage 2; and similarly, the beads and 'wire spicules' in Fig. 5, Stage 1 vs. Stage 2). In very simplified terms, we can say that the 'overall fluidity' of the tested slurries abruptly increased. On the other hand, surfactant concentrations of about $0.5 \mathrm{wt} . \%$ o were not strong enough to cause the 'syrupy' behaviour of solutions and slurries, which is typical for relatively high surfactant concentrations. The lowest stromatactum to sub-stromatactum macroporosity, calculated from 100 repetitions, ranged between 3 and 15 (5) v.\% for the 'clastic mixture' (Fig. 4: Stage 2), and between 1 and 10 (3) v.\% for the 'sponge-spicule mixture' (Fig. 5: Stage 2). Again, there were negatively skewed distributions in both mixtures, i.e. only a few stromatactis cavities were much larger than the others (Fig. 3).

Whenever the concentrations were around $1 \mathrm{wt} . \%$, as illustrated by the experiments at the $1.2 \mathrm{wt} . \%$ concentration level (Stage 3; Figs 4, 5), the stromatacta were significantly restored. Multi-layered, flat and linked stromatacta were the typical products of these conditions. The residual particulate suspensions within the voids were even finer than in the previous stage, but their homogeneity was dis- turbed by thin strings of downward directed flows with the medium-sized mud-forming particles. These particles poured from narrow chimneys and adjacent pores above the stromatactum ceilings. Their deposition created smooth cavity floors, the deposition of which preceded that of the finest residual suspensions (Stage 3; Figs 4, 5). The overall magnitude of the restored stromatactis voids was almost comparable to the initial stage, in which the water was free of surfactants. This restoration was particularly relevant to the 'sponge spicule mixture', and to a lesser degree the 'clastic mixture' (e.g., Fig. 4: 3B). The Stage-3 stromatacta shapes differed from those of Stage 1 . In both mixtures, the frequency maxima of cumulative stromatacta volumes (20 and 16 v.\%, respectively) were shifted toward larger voids, so that the distributions were positively skewed (Fig. 3).

The full restoration of robust stromatacta formations occurred at concentrations around $1.5 \mathrm{wt} . \%$ o. When the concentrations reached $1.8 \mathrm{wt} \%$ o, the cumulative volumes and particularly the size of individual stromatacta were even larger than in the initial cases (Stage 4; Figs 4,5$)$. In addition, the stromatactis shapes were quite comparable to their natural counterparts (e.g., Hladil 2005). Another series of experiments (N 100) were carried out at the $1.8 \%$ concentration level, during which the surfactant concentration was gradually increased $(2.4,3.0$ and $3.6 \mathrm{wt} . \% \mathrm{o}$ ). A cumulative stromatacta macroporosity of 25-30 v.\% was regularly achieved within this range of concentrations. Interestingly, the frequency distributions were nearly symmetrical and apparently narrower than those in the previous steps. Perhaps the most significant finding was that the magnitude of stromatacta remained quite constant in the concentration range from 1.8 to 3.6 wt.\%o (Plateau; Fig. 3).

The behaviour of the settling slurries and sub-consolidated sediments at concentrations of $3.6 \mathrm{wt} . \%$ and higher differed from that of the lower concentrations. The slurries were more 'syrupy', and they contained slowly changing, large inhomogeneities with coarse and fine-grained materials. The very slow and homogeneous 'raining' of mediumsized particles from overlying pores was closely coupled to sedimentation of the residual suspensions. This caused particle-laden flows inside the forming sediment, which often thickened and filled the stromatactis cavities. In extreme cases, the voids were completely filled by the deposition of fluidized, finer-grained flows. In addition, this sort of infill was often completed by further fine-grained particles that poured from the uppermost layer of the bed (compare the experimentally obtained structures with their slightly altered natural counterparts in Fig. 6). This process was marked by the formation of 'funnels' (fnl; e.g., Fig. 6: 1B). The final products were specific arrays of patches only remotely resembling the stromatacta or stromatactis structures. 

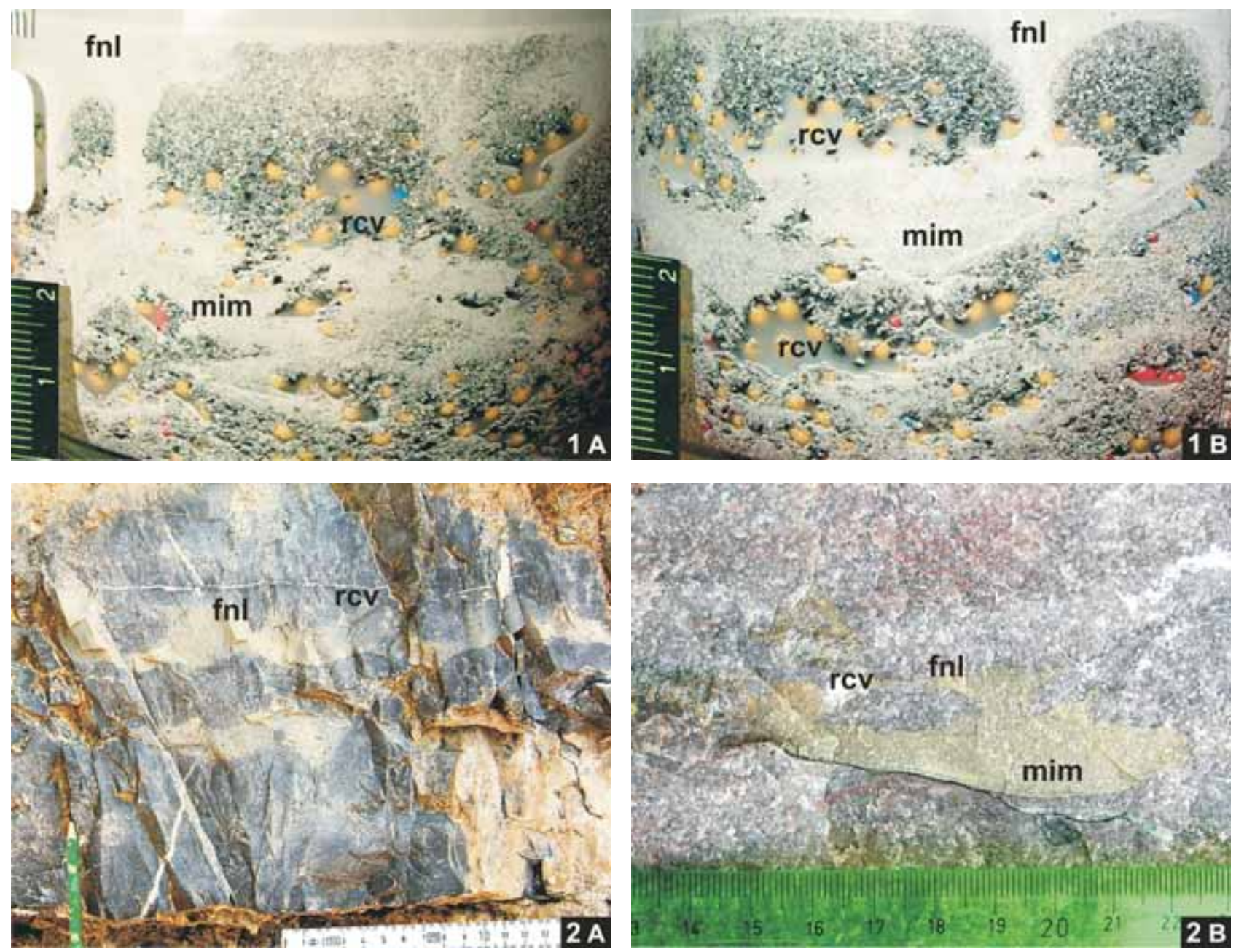

Figure 6. The artificial stromatacta patterns obtained in supercritical surfactant concentrations (upper two photographs; examples 1A and B), and the comparison of them with structures in natural carbonate sediments (the lower two; examples $2 \mathrm{~A}$ and B). $\bullet 1 \mathrm{~A}, \mathrm{~B}-\mathrm{results}$ of the experimental sedimentation of the 'sponge-spicule mixture' at surfactant concentration levels greater than $3.6 \mathrm{wt} . \%$. These structures formed 6-8 minutes after deposition. The residual cavities ( $\mathrm{rcv}$ ) are preserved only on the top of the former stromatactum holes and in a few irregular positions, whereas most of the space was filled by a variety of poorly layered to mixed infiltrated matter ( $\mathrm{mim})$. The upper parts of these structures are marked by partial shapes resembling nailheads or funnels (fnl). They correspond to more persistent granular flows within the consolidating sediment. $\bullet 2 \mathrm{~A}$, B - the mid-level zones of some natural calciturbidite beds also display these specific features. The imperfectly outlined, massive infillings are comparable to the shapes of stromatacta, but their upper parts are typically marked by partial shapes resembling funnels. These two examples from the lower third of the Praha Formation in the Reporyje Quarry near Prague (Lower Devonian, Prague Synform, Barrandian area) seem to be natural counterparts of the experimentally obtained structures, notwithstanding the slight changes due to compaction and neomorphism (Fe-calcite, dolomite, clay-minerals).

\section{Discussion}

\section{General effects of increasing concentrations of surfactants on the viscosity and porosity of the sediments}

The presence of glycerol-based surfactants, and glycerol itself, cause a strong, often strongly nonlinear increase in viscosity with increasing concentration in aqueous solutions (e.g., Shankar \& Kumar 1994). A similar significant increase of viscosity occurred with the gradual addition of surfactants, in which several amounts of sodium chloride were dissolved in this water; but the viscosity of these and similar aqueous solutions decreases with rising temperature (e.g., Chenlo et al. 2004). Many of the more complex polymer and copolymer, natural or artificial surfactants also act in this way (e.g., Lin et al. 2000), but the rising concentrations of surfactants in very complex fluids may lead to dramatic increases in viscosity and subsequent stabilization, or even subsequent decrease (Gelbart \& Ben-Shaul 1996). The fast beginning and much slower continuation of the changes that occur with increasing concentrations of surfactants can be understood as the interfaces between phases quickly becoming 'saturated'. This can be demonstrated using simple, easily reproducible experiments (e.g., Gatton 2006) in which constant amounts of 
graded detergent/water solutions are pushed through cylinders with dropper tips. With graded dosages of a blend of detergents (e.g., commercially available Dawn, Jar, etc.), the size of drops becomes significantly smaller while the quantity of these drops increases. However, this is valid only for the first steps, as negligible changes (plateau values) are soon encountered. These general properties of surfactant-bearing complex fluids have implications for interpreting the present experiments.

Firstly, the seemingly unique behaviour of complex particulate slurries with the addition of surfactants is not dissimilar to the behaviour of the fluid components themselves. This indicates that the formation of stromatacta patterns may significantly depend on liquid slurry stages, i.e. the processes that precede the early consolidation stages of the sediment. Secondly, the particularly high viscosity values in salty but relatively cold water containing surfactants would seem to engender favourable environments for the deposition of stromatacta/stromatactis host rocks. Thirdly, they suggest that relatively slight concentrations of surface active agents can readily act as 'stromatacta destructors'. Similar principles have already been used for reducing the pore spaces in settling particulate suspensions, e.g., kaolinite and nonionic polyethylene oxide polymers (Mpofu et al. 2003).

\section{Durability of stromatacta cavities}

As shown by Hladil (2005) and Hladil et al. (2006), there are also many other limitations on the production of artificial, sufficiently sized, durable stromatacta formations. The fundamental condition for producing sediment with stromatacta is an appropriate mixture of particulate solids. These materials must be highly polydisperse and multimodal, generally within the clay-silt or silt-sand size ranges, and have highly angular and indented surfaces. Any reduction in these material characteristics affects the stability of the resulting stromatacta. Such stromatacta can collapse immediately during the earliest stages of sediment compaction ( $c f$. Fig. 1B-D), or after longer time spans of minutes or even weeks ( $c f$. Fig. 1G, H). The presence of excessive amounts of rounded/sub-rounded particles of any size strongly inhibits the stromatacta-forming processes due to the reduction of inhomogeneities in the settling suspensions, and the lowering of shear stress and internal friction in the sediment.

Sedimentation mode is another significant condition affecting this process. For example, any mode of sedimentation from highly turbulent, low-density flows that move over the substrate cannot produce stromatacta due particularly to the conditions of strong lateral shear. The same is true for the gravitational deposition of high-density granular flows. The formation of stromatacta strictly requires the conditions of direct sedimentation of suspensions, concurrent with syn- to post-depositional water escape, after the entire flows have slowed or collapsed ( $c f$. M4 division of slurry beds, Lowe et al. 2003, cf. Fig. 1U, herein). These conditions entail the considerable reduction of unidirectional lateral shear stress. The stirred but settling slurry layer thickens, but is covered by an even thicker cover of low permeability, formed by particles deposited from lowdensity suspensions above the slurry. Sedimentation-driven convections, instabilities and lateral inhomogeneities are produced within the confined slurry layer ( $c f$. Lowe \& Guy 2000, Lowe et al. 2003, and Hladil et al. 2006). Any differences from an ideal slurry settling mode either prevent the formation of stromatacta, or else form rudimentary ones that are easily destroyed. In uncemented stromatacta-bearing sediments, the considerable deformation, reworking or total destruction of stromatacta would be caused by sliding shear failure. In slightly cemented varieties, however, deformation and the opening of other voids is possible (e.g., Lees 1964). The occurrence of relatively well preserved stromatacta/stromatactis structures in natural carbonate rocks is ascribed to the potential of such rocks for early lithification by recrystallization or cementation.

\section{Conclusions}

The present study on the relations between stromatacta and surfactants does not confirm the simplest hypotheses that increased concentrations of surfactant solutes could lead either to continuous weakening or continuous strengthening of the stromatacta formations in appropriate particulate slurries and sediments. On the contrary, more complex relationships were found. A short interval of rapid changes (and particularly slight stromatacta formations) regularly occurs with relatively low doses of surfactant-bearing concentrates. This is explained by the release of internal stress and reduced friction. The restoration of the stromatacta formations with relatively higher concentrations of surfactant solutes is most likely related to fluid viscosity, which increases very quickly with linearly increasing concentrations of surfactant compounds. A plateau stage was observed over a wide concentration range, in which the transformation of large turbulent domains into bulky inhomogeneities were combined with the tight packing of grains in patches, vaults (arching effect) and quasi-rhombically arranged, reticular zones. The stromatacta cavities in this stage were large and resistant, and their shapes were very similar to many natural stromatactis examples. The supercritical stromatacta-forming systems (exceeding the plateau range of the surfactant concentration values) present a problem for the origin and durability of stromatacta. The thickening slurries of these systems are typically syrupy; they still generate bulky inghomogeneities, but do so with fast energy 
dissipation that contrasts with the protracted granular flows in the consolidating sediment. In place of stromatacta, there are only patches and infills that resemble stromatactis shapes.

\section{Acknowledgements}

We gratefully acknowledge the support of the Grant Agency of the Academy of Sciences of the Czech Republic (particularly project No. IAAX00130702, and institute plan No. AV0Z30130516). The authors also thank Malcolm W. Wallace (University of Melbourne) and Brian R. Pratt (University of Saskatchewan) for making formal reviews with valuable comments that provided clear strategies for the improvement of this paper, and we especially appreciate informal comments by Fritz Neuweiler (University of Laval, Québec) and many other colleagues.

\section{References}

Aubrecht, R., KRobicki, M. \& SCHLÖGL, J. 2006. Middle to Upper Jurassic stromatactis mud-mounds in the Pieniny Klippen Belt, Carpathians. $7^{\text {th }}$ International Congress of the Jurassic System, Kraków, Volumina Jurassica 4, 76.

Aubrecht, R., Szulc, J., Michalík, J., SchlöGl, J. \& WAGREICH, M. 2002. Middle Jurassic stromatactis mud-mound in the Pieniny Klippen Belt (Western Carpathians). Facies 47, 113-126.

BAtHURST, R.G.C. 1982. Genesis of stromatactis cavities between submarine crusts in Palaeozoic carbonate mud buildups. Journal of the Geological Society, London 139, 165-181.

Boulvain, F. 2001. Facies architecture and diagenesis of Belgian Late Frasnian carbonate mounds. Sedimentary Geology 145, 269-294.

BourQue, P.A. \& GignAC, H. 1983. Sponge-constructed stromatactis mud mounds, Silurian of Gaspé, Québec. Journal of Sedimentary Petrology 53, 521-532.

Bourque, P.A., Neuweiler, F. \& Boulvain, F. 2004. The mudmound system: products and processes. $32^{\text {nd }}$ International Geological Congress, Florence, Italy. CD-ROM Abstracts 2, 1079.

Chenlo, F., Moreira, R., Pereira, G. \& Bello, B. 2004. Kinematic viscosity and water activity of aqueous solutions of glycerol and sodium chloride. European Food Research Technology 219, 403-408.

Delecat, S. \& Reitner, J. 2005. Sponge communities from the Lower Liassic of Adnet (Northern Calcareous Alps, Austria). Facies 51, 385-404.

Dupont, E. 1882. Sur l'origine des calcaires dévoniens de la Belgique. Bulletin Académie Royal des Sciences de la Belgique, Lettres et Beaux-Arts de Belgique $3^{\circ}$ série, II, 1881(9-10), 264-280.

GatTon, M. 2002. How does detergent concentration affect the size of water drops? The Middle School Science, 7 July 2006, http://middleschoolscience.org/Download/surftens.doc, 1-9.

Gelbart, W.M. \& Ben-Shaul, A. 1996. The 'new' science of 'complex fluids'. Journal of Physical Chemistry 100, 13169-13189.

HLADIL, J. 2005. The formation of stromatactis-type fenestral structures during the sedimentation of experimental slurries a possible clue to a 120-year-old puzzle about stromatactis. Bulletin of Geosciences 80, 193-211.

HLADIL, J. \& RỦŽIČKA, M. 2006. Pattern formation in geological sediments: field observations versus experiments in a glass of water. In Geurts, B.J., Clercx, H.J.H. \& UiJttewaAl, W.S.J. (eds) Particle-laden flow from geophysical to Kolmogorov scales, 2006 Twente EUROMECH Colloquium 477 Paper, A11.

HLADIL, J., RƯŽIČKA, M. \& KoptíKOVÁ, L. 2006. Stromatactis cavities in sediments and the role of coarse-grained accessories. Bulletin of Geosciences 81, 123-146.

Kaufmann, B., Reinhold, C. \& Schauer, M. 1999. Concentric-zoned calcite cements of Middle Devonian carbonate mounds of the Mader Basin (eastern Anti-Atlas, Morocco) - a combined cathodoluminescence and microprobe study. Neues Jahrbuch für Geologie und Paläontologie, Abhandlungen 214, 95-110.

Kaufmann, B. \& WendT, J. 2000. Calcite cement successions in Middle Devonian (Givetian) carbonate mud buildups of the southern Ahnet Basin (Algerian Sahara). Carbonates and Evaporites 15, 149-161.

Krause, F.F., Scotese, C.R., Nieto, C., Sayegh, S.G., HopKINS, J.C. \& MEYER, R.O. 2004. Paleozoic stromatactis and zebra carbonate mud-mounds: global abundance and paleogeographic distribution. Geology 32, 181-184.

LEES, A. 1964. The structure and origin of the Waulsortian (Lower Carboniferous) 'reefs' of west-central Eire. Philosophical Transactions of the Royal Society of London B 247, 483-531.

LeEs, A. \& Miller, J. 1985. Facies variation in Waulsortian buildups. Part 2. Mid-Dinantian buildups from Europe and North America. Geological Journal 20, 159-180.

Lin, Y., KAIFU, L. \& RonghuA, H. 2000. A study on P(AM-DMDA) hydrophobically associating water-soluble copolymer. European Polymer Journal 36, 1711-1715.

LOWE, D.R. 2000. Sediment texture and flow processes as interactive controls on the architecture and properties of deep-water deposits with examples from the Britannia Formation (Lower Cretaceous), North Sea. 2000 AAPG Annual Meeting, Paper 2354.

Lowe, D.R. \& GuY, M. 2000. Slurry-flow deposits in the Britannia Formation (Lower Cretaceous), North Sea: a new perspective on the turbidity current and debris flow problem. Sedimentology 47, 31-70.

Lowe, D.R., GuY, M. \& PALfREY, A. 2003. Facies of slurry-flow deposits, Britannia Formation (Lower Cretaceous), North Sea: implications for flow evolution and deposit geometry. Sedimentology 50, 45-80. 
MonTY, C.L.V. 1995. The rise and nature of carbonate mudmounds: an introductory actualistic approach, 11- 48. In Monty, C.L.V., Bosence, D.W.J., Bridges, P.H. \& Pratt, B.R. (eds) Carbonate mud-mounds: their origin and evolution. International Association of Sedimentologists, Special Publication 23.

Mpofu, P., AdDAI-MENSAH, J. \& RALSTON, J. 2003. Investigation of the effect of polymer structure type on flocculation, rheology and dewatering behaviour of kaolinite dispersions. International Journal of Mineral Processing 71, 247-268.

NeuweILER, F. \& BernoulLI, D. 2005. Mesozoic (Lower Jurassic) red stromatactis limestones from the Southern Alps (Arzo, Switzerland): calcite mineral authigenesis and syneresis-type deformation. International Journal of Earth Sciences 94, 130-146.

Neuweiler, F., Bourque, P.A. \& Boulvain, F. 2001. Why is stromatactis so rare in Mesozoic carbonate mud mounds? Terra Nova 13, 338-346.

PRATT, B.R. 1982. Stromatolitic framework of carbonate mudmounds. Journal of Sedimentary Petrology 52, 1203-1227.

PRATT, B.R. 1995. The origin, biota and evolution of deep-water mudmounds, 49-123. In MonTy, C.L.V., Bosence, D.W.J., BRIDGES, P.H. \& PRATT, B.R. (eds) Carbonate mud-mounds: their origin and evolution. International Association of Sedimentologists, Special Publication 23.
SANDERS, D. 2003. Syndepositional dissolution of calcium carbonate in neritic carbonate environments: geological recognition, processes, potential significance. Journal of African Earth Sciences 36, 99-134.

Schmid, D.U., LeINFELDER, R.R. \& Nose, M. 2001. Growth dynamics and ecology of Upper Jurassic mounds, with comparisons to Mid-Palaeozoic mounds. Sedimentary Geology 145, 343-376.

SHANKAR, P.N. \& Kumar, M. 1994. Experimental determination of the kinematic viscosity of glycerol-water mixtures. Proceedings of the Royal Society of London A, Mathematical, Physical and Engineering Sciences 444(1922), 573-581.

Verdugo, P., Alldredge, A.L., Azam, F., Kirchman, D.L., PASSOW, U. \& SANTSCHI, P.H. 2004. The oceanic gel phase: a bridge in the DOM-POM continuum. Marine Chemistry 92, $67-85$.

WALLACE, M.W. 1987. The role of internal erosion and sedimentation in the formation of stromatactis mudstones and associated lithologies. Journal of Sedimentary Petrology 57, 695-700.

Woods, A.D. 2002. The role of subcutaneous fluid escape in the formation of a cavity system within a Mid-Ordovician (Whiterockian) mud mound at Meiklejohn Peak, southwestern Nevada. 2002 GSA Denver Annual Meeting, Session 151, Paper 151-13. 